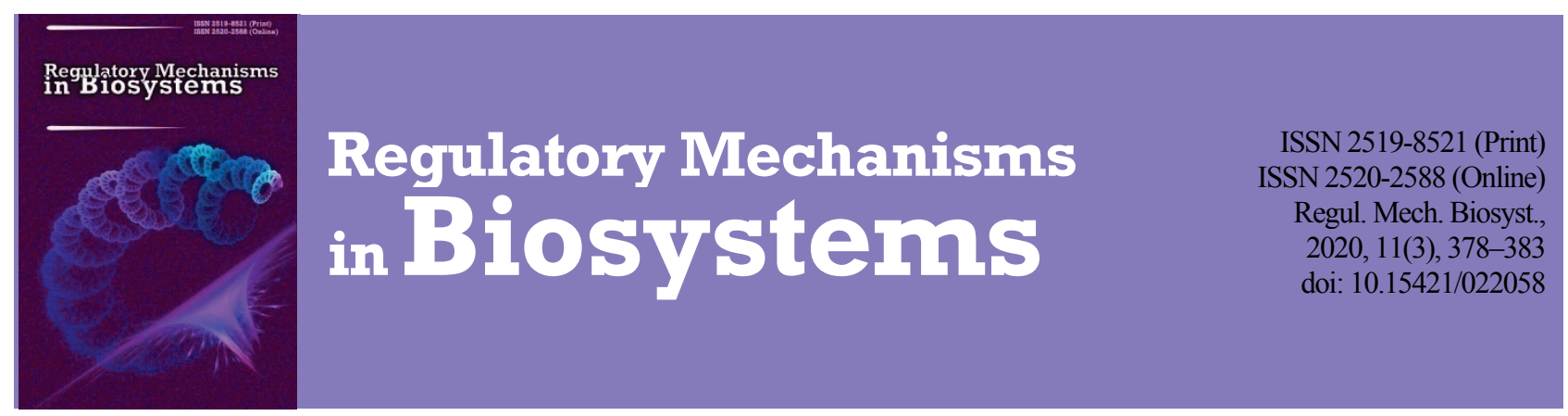

\title{
Morphological characteristic of Skrjabinema ovis (Nematoda, Oxyuridae) obtained from domestic sheep
}

\author{
V. V. Melnychuk*, O. I. Reshetylo** \\ *Poltava State Agrarian Academy, Poltava, Ukraine \\ **Sumy National Agrarian University, Sumy, Ukraine
}

Article info

Received 27.06.2020

Received in revised form 22.07.2020

Accepted 25.07.2020

Poltava State

Agrarian Academy,

Skovorody st., 1/3,

Poltava, 36003, Ukraine.

Tel.: +38-066-674-78-09.

E-mail:

melnychyk86@ukr.net

Sumy National

Agrarian University

G. Kondratieva st., 160,

Sumy, 40000, Ukraine.

Tel.: $+38-099-100-45-48$

E-mail:

reshetilooi@ukr.net

Melnychuk, V. V., \& Reshetylo, O. I. (2020). Morphological characteristic of Skrjabinema ovis (Nematoda, Oxyuridae) obtained from domestic sheep. Regulatory Mechanisms in Biosystems, 11(3), 378-383. doi:10.15421/022058

Skrjabinemosis is a widely prevalent helminthiasis of sheep, goats and wild ruminants. It is caused by Skrjabinema ovis Skrjabin, 1915. Parasitization by S. ovis induces inflammatory processes of the large intestine, in skin around the anus and tail base, resulting in reduced productivity and weight loss. The measures of prevention and control of skrjabinemosis on sheep farms depend on the timely and accurate diagnosis, based on the reliable identification of nematodes. We studied the identification morphometric characters of this species The nematodes were obtained from the large intestine of 710 pasture-kept sheep (Ovis aries) on farms of Kyiv, Poltava and Zaporizhzhia regions ( Central and South-Eastern Ukraine). In total, 5723 adult S. ovis nematodes were collected, 1981 of which were males and 3742 were females. Sexual dimorphism was found in S. ovis both in metric and morphological parameters. The size dimorphism is characterized by values larger by $43.9-64.6 \%$ of 11 parameters in females compared to males. The differential characters of mature $S$. ovis males and females are morphological specifics of the mouth organ complex and the distribution of cuticular formations on the head end of the parasite. The lips of the female nematodes are anchor-shaped and adorned with tooth-like lamellae, and the lips of the males are oval and lack the tooth-like lamellae. Cuticular nodes on the head ends of the females are considerably longer and wider than in the males. The species-specific morphological characters of the males are the features of morphology and sizes of the pseudobursa, the shape and length of the spicule and gubernaculum, and their width parameters in different areas. In the identification of females, the morphology of the vulva and tail end, and the metric parameters of the location of the vulva, anus, and sizes of eggs in the uterus should be considered. Additional metric and morphological parameters are presented for use in the differentiation of males and females for better identification.

Keywords: skrjabinemosis; helminths; differential characters; metric parameters.

\section{Introduction}

The main aim of sheep farming is a full utilization of the biological potential of meat, wool and dairy productivity of sheep breeds (Rasali et al., 2006; Banerjee et al., 2009; Anteneh \& Yadav, 2017). One of the approaches used is careful monitoring and prediction of the parasitological situation, the implementation of measures for the prevention and treatment of invasive diseases, especially nematodes of the gastrointestinal tract of sheep. It is well-known that the biotic, abiotic and technological factors directly affect the activity of epizootic processes of animal helminthiases, including those of sheep (Vlassoff et al., 2001; Tariq et al., 2008; Roeber et al., 2013; Ibrahim et al., 2014; Boyko et al., 2016; Zazharska et al., 2018).

Sheep helminths are widely prevalent and form parasitic systems with multiple levels of protection. They cause infectious diseases that are stable and enzootic in various countries in most of the natural climatic zones. There are reports of significant prevalence of the parasitic Skrjabinema ovis (Skrjabin, 1915) nematodes in sheep. Thus, the prevalence of $S$. ovis in sheep ranged 2.2-12.0\%. The maximum infection rates were found in the 1.0-1.5 year old age group (Bahadori et al., 2007; Naem \& Gorgani, 2011). In the south-east of Spain, $10.28 \%$ of the examined sheep were infected with this species, the infection intensity reaching 46.3 individuals per host (Ruiz de Ybáñez et al., 1999). In a number of regions of Pakistan, skrjabinemosis was diagnosed only in 1.2\% sheep (Farooq et al., 2012). In Sudan, the prevalence of skrjabinemosis in sheep was $6.7 \%$, and the intensity ranged 1-74 individuals per host (Abdelnabi et al., 2005). Skrja- binemosis is also found on sheep farms in Italy, Brazil, Africa, and Macedonia (Balbo et al., 1977; Theodoridis et al., 2000; Belem et al., 2005; de Souza et al., 2012). This prevalence of skrjabinemosis is likely related to the biological features of the parasite. Its life cycle lacks an intermediate host. It has been observed that mature Skrjabinema females passively crawl from the rectum to the perianal skin of the host, and lay eggs, in which the larvae develop and molt twice. After that, the egg becomes infectious, and is released into the environment where the alimentary infection of hosts occurs (Schad, 1957; Anderson, 2000).

Post-mortem examinations are most significant methods of diagnostics for species identification of helminth pathogens and assessment of their numbers. In veterinary practice this kind of study is the final link in the medical and diagnostic process. It allows one to verify the life-time diagnosis and the adequacy of the prescribed treatment. The post-mortem diagnostics of helminths is the most reliable method. It is based on the results of parasitological and anatomical dissections of animals and their organs, and in the process of post-mortem inspection of bodies. The results of morphological and metric studies of the observed helminths are highly important for their differentiation, and for the questions of systematics, biology, and species identification, including for the pathogen of sheep skrjabinemosis (Shahlapoor, 1965; Ivashkin et al., 1998; Popiołek et al., 2009; Li et al., 2019).

The taxonomic differentiation of mature nematodes is based on the morphological specifics of their body, head end, position of lips in the mouth capsule, and the tail end, shape and size of spicule, bursa and gubernaculum in males. In females, the morphology of copulatory apparatus, 
vulva location and egg size while in the uterus are taken in consideration. There are also suggestions for using the length and width of the body, bulbus, esophagus, and wing-like formations on the head end. However, the reported data on the metric parameters of $S$. ovis are scarce and rather variable (Abdussalam, 1938; Skrjabin et al., 1960; Andrews, 1969). Thus, a morphometric study of $S$. ovis, obtained from sheep, would have scientific and practical value, because of the new data on the species identification of these parasites, and enhanced diagnostics of skrjabinemosis.

The aim of the present work was to study the differential morphological and metric parameters of the adult males and females of S. ovis nematodes, obtained from sheep (Ovis aries).

\section{Materials and methods}

Parasitological analysis of S. ovis nematodes was conducted in 20152020. The helminths were obtained during helminthological investigation of the large intestine of 710 domestic sheep (Skriabyn, 1928) from sheep farms in Kyiv, Poltava and Zaporizhzia regions (Central and SouthEastern Ukraine). After collection from the intestine, the nematodes were washed in $0.9 \%$ solution of $\mathrm{NaCl}$ and fixed according to standard technique in 70\% ethanol (Ivashkin et al., 1971). Roundworm species were identified by morphological features according to (Skrjabin et al., 1960; Ivashkin et al., 1998). In total, 5723 adult $S$. ovis nematodes were collected, 1981 of which were males and 3742 were females.

The metric parameters of adult $S$. ovis roundworms were measured using ImageJ for Windows ${ }^{\circledR}$ (version 2.00) in interactive mode using $\times 5$, $\times 10, \times 40, \times 100$ objectives and $\times 10$ photo eyepiece. To calibrate the image analyzer, the ruled scale of an ocular micrometer was coincided with the scale of the stage micrometer included in a MikroMed microscope kit. Photomicrographs were taken using a 5 Mpix digital camera mounted on the MikroMed (China) microscope.

Standard deviation (SD) and mean values (x) were calculated. Reliability of the differences in mean values for the studied groups of nematodes was determined by the method of one-way analysis of variance using the Fisher test, with $\mathrm{P}<0.05$ level of significance.

\section{Results}

The nematodes of the species S. ovis (Skrjabin, 1915) are characterized by significant morphological sexual dimorphism. The body of the female nematode is white, filiform, slightly tapered to the head end and more tapered to the tail end. The male roundworms have hook-shaped bodies, with a straight anterior part and bent posterior part (Fig. 1).

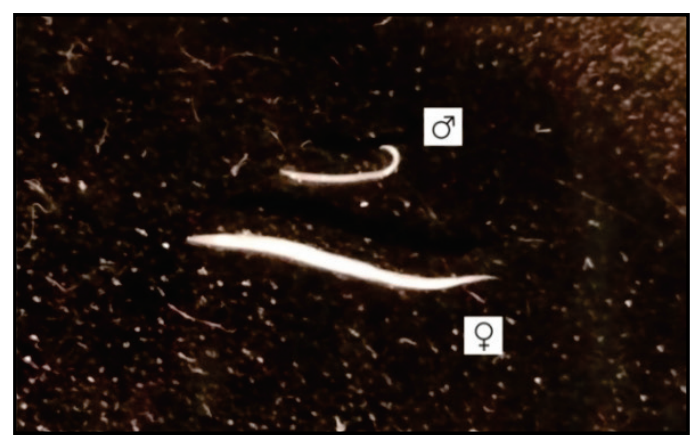

Fig. 1. General view of Skrjabinema ovis

The head end of male and female Skrjabinema nematodes has two lateral wing-shaped cuticular nodes. Their bases are located at the lip bases, and their ends at the esophagus area. More narrow cuticular wings are located posterior to them. Those run along the lateral lines of the body and end in the area between the anus and the tail end. The mouth opens into the esophagus, which is divided into two clearly distinct parts: cylindrical anterior and behind that the spherical bulbus. We have observed that the wing-shaped nodes are significantly narrower and shorter in males than in females (Fig. 2).

The head end of $S$. ovis is adorned with a complex formation of mouth organs. The mouth opening is surrounded by three symmetrical large lips. Each lip consists of the median and two lateral parts. The me- dian part of each lip extrudes above the mouth ring and branches into anterior and posterior wedges. These wedges are divided by a deep indentation, hence the illusion of six lips. The anterior wedge of each lip consists of two parts which make up a pyramid, pointed anteriorly. The narrow sides of pyramids face outwards, and the wider sides are positioned to the inside and laterally to mouth opening. The lips of males and females are morphologically different. In females, lips are anchor-shaped, and there are single pairs of tooth-like lamellae, pointed to the centre of the mouth opening, on their inner sides. The lips of males are oval and lack the toothlike lamellae (Fig. 3).

Aside from the morphological specifics, there are significant metric differences in the sexual dimorphism of $S$. ovis. By 11 parameters, the females were significantly $(\mathrm{P}<0.001)$ larger than males (Table 1$)$.

\section{Table 1}

Morphometric parameters

of sexual dimorphism in Skrjabinema ovis $(\mathrm{x} \pm \mathrm{SD} ; \mathrm{n}=15)$

\begin{tabular}{|c|c|c|}
\hline Parameters & $\hat{0}$ & q \\
\hline Length of body, $\mathrm{mm}$ & $3.1 \pm 0.2$ & $6.3 \pm 0.5^{* * *}$ \\
\hline Length of the lateral cuticular nodes, $\mu \mathrm{m}$ & $100.1 \pm 7.1$ & $282.9 \pm 12.6^{* * *}$ \\
\hline \multicolumn{3}{|l|}{ Width of body in the area of, $\mu \mathrm{m}$ : } \\
\hline- lips & $55.2 \pm 4.9$ & $104.0 \pm 7.6^{* * *}$ \\
\hline - cuticular nodes & $103.8 \pm 4.0$ & $220.5 \pm 23.9^{* * *}$ \\
\hline - middle of the body & $218.0 \pm 7.9$ & $323.2 \pm 34.3^{* * *}$ \\
\hline Total length of esc & $379.0 \pm 10.5$ & $731.1 \pm 22.6^{* * *}$ \\
\hline Length of anterior cylindrical part of esophagus, $\mu \mathrm{m}$ & $279.1 \pm 7.5$ & $552.6 \pm 35.2^{* *}$ \\
\hline $\begin{array}{l}\text { Width of anterior cylindrical part of esophagus in } \\
\text { the middle, } \mu \mathrm{m}\end{array}$ & $36.6 \pm 2.8$ & $71.1 \pm 3.4^{* * *}$ \\
\hline $\begin{array}{l}\text { Width of esophagus at the transition from the } \\
\text { anterior cylindrical part to the posterior bulbous } \\
\text { part, } \mu \mathrm{m}\end{array}$ & $23.9 \pm 1.9$ & $54.9 \pm 4.1^{* * *}$ \\
\hline Length of bulbus, $\mu \mathrm{m}$ & $99.8 \pm 10.4$ & $178.4 \pm 29.4^{* * *}$ \\
\hline Width of bulbus, $\mu \mathrm{m}$ & $86.5 \pm 2.9$ & $154.2 \pm 5.8^{* * *}$ \\
\hline $\begin{array}{l}\text { Ratio of the lengths of the anterior cylindrical part } \\
\text { of esophagus to the posterior bulbous part }\end{array}$ & $2.8: 1$ & $3.2: 1$ \\
\hline
\end{tabular}
of esophagus to the posterior bulbous part

Note: $* * *-\mathrm{P}<0.001-$ compared to values of $\partial$ S. ovis.

Thus, the body length of females was $6.3 \pm 0.5 \mathrm{~mm}$, which was larger by $50.7 \%$ than in males $(6.3 \pm 0.5 \mathrm{~mm})$. Accordingly, the females were wider in the lip area, at the cuticular node area and in the middle of body by $52.9-57.4 \%$ than males. The parameters of length of lateral cuticular nodes at the head end of the nematodes were larger in females by $64.6 \%$, which is confirmed by morphological studies, too. The esophagus was significantly larger in females than in males. It was longer by $48.1 \%$. The length of the anterior cylindrical part of the esophagus in females was $552.6 \pm 35.2 \mu \mathrm{m}$ (longer by $49.4 \%$ than in males), and the length of the posterior bulbous part of the esophagus in females was $178.4 \pm 29.4 \mu \mathrm{m}$ (longer by $44.0 \%$ than in males). The width parameters of esophagus in females were also higher than in males, in the middle of the anterior cylindrical part by $48.5 \%$, at the transition of that part into the bulbous part by $56.4 \%$, and in the middle of the bulbus by $43.9 \%$. Thus, the ratio of the length of anterior part of esophagus to the posterior one was $3.2: 1$ in males, and $2.8: 1$ in females.

The specific morphological characters of $S$. ovis males include the morphological features of pseudobursa, spicule, gubernaculum (Fig. 4), and their metric parameters (Table 2).

The tail end of Skrjabinema males ends with the pseudobursa, which consists of membrane, terminal tail protrusion, and one pair of pre-anal and one pair of post-anal ribbed papillae. Their apexes are shaped like coronas with three conic processes. The parameters of length and width of pseudobursa were $185.6 \pm 15.5$ and $120.7 \pm 8.0 \mu \mathrm{m}$, respectively, their ratio was $1.5: 1$,i.e. pseudobursa is elongated. The morphological features of males also include the presence of one pair of elongated, stalk-shaped post-anal papillae between the tail protrusion and the anus. There are small papillae in the cloacal area, which support pseudobursa. There is one spicule $94.4 \pm 4.6 \mu \mathrm{m}$ in length, arrow-shaped. The spicule lies in the groove of the gubernaculum, the mean length of which was $24.4 \pm 2.1 \mu \mathrm{m}$. In the identification of this species, we also suggest using the parameters of width at the proximal end of the spicule $(5.7 \pm 0.2 \mu \mathrm{m})$ and in the middle of the spicule $(4.4 \pm 0.2 \mu \mathrm{m})$, and the parameters of width of the proximal end of the gubernaculum $(5.3 \pm 0.1 \mu \mathrm{m})$ and in its middle $(4.0 \pm 0.4 \mu \mathrm{m})$. 

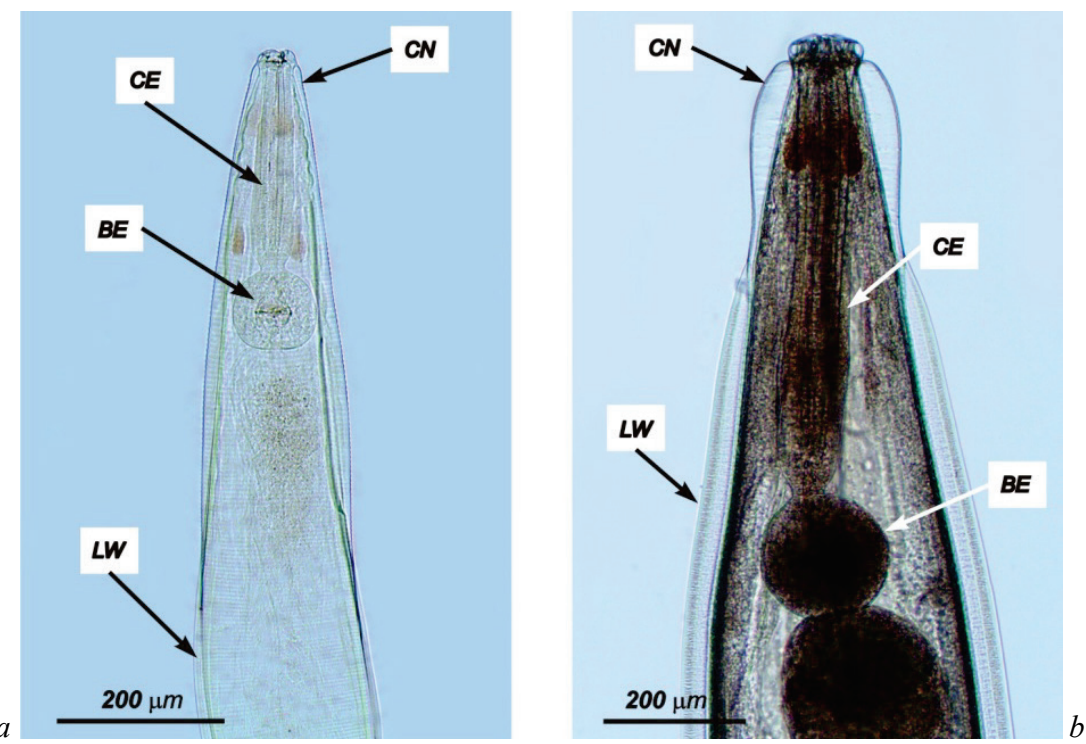

Fig. 2. Head end of Skrjabinema ovis: $a-\hat{O}, b-+; C N$-cuticular nodes, $L W$-lateral wings, $C E$ - cylindrical part of esophagus, $B E$ - posterior part of esophagus, spherical bulbus
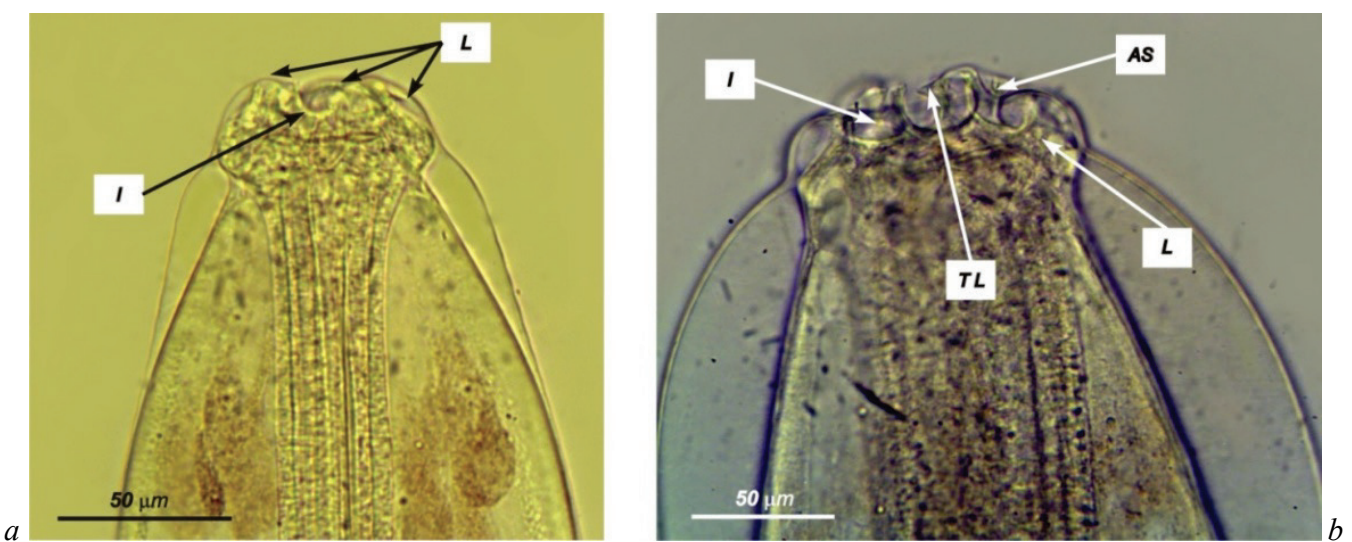

Fig. 3. Mouth organs of Skrjabinema ovis: $a-\partial^{\lambda}, b-+; L-$ lips, $A S$ - anchor-shaped lips,

$I$-indentation between the anterior and posterior lip wedges, $T L$ - tooth-like lamella

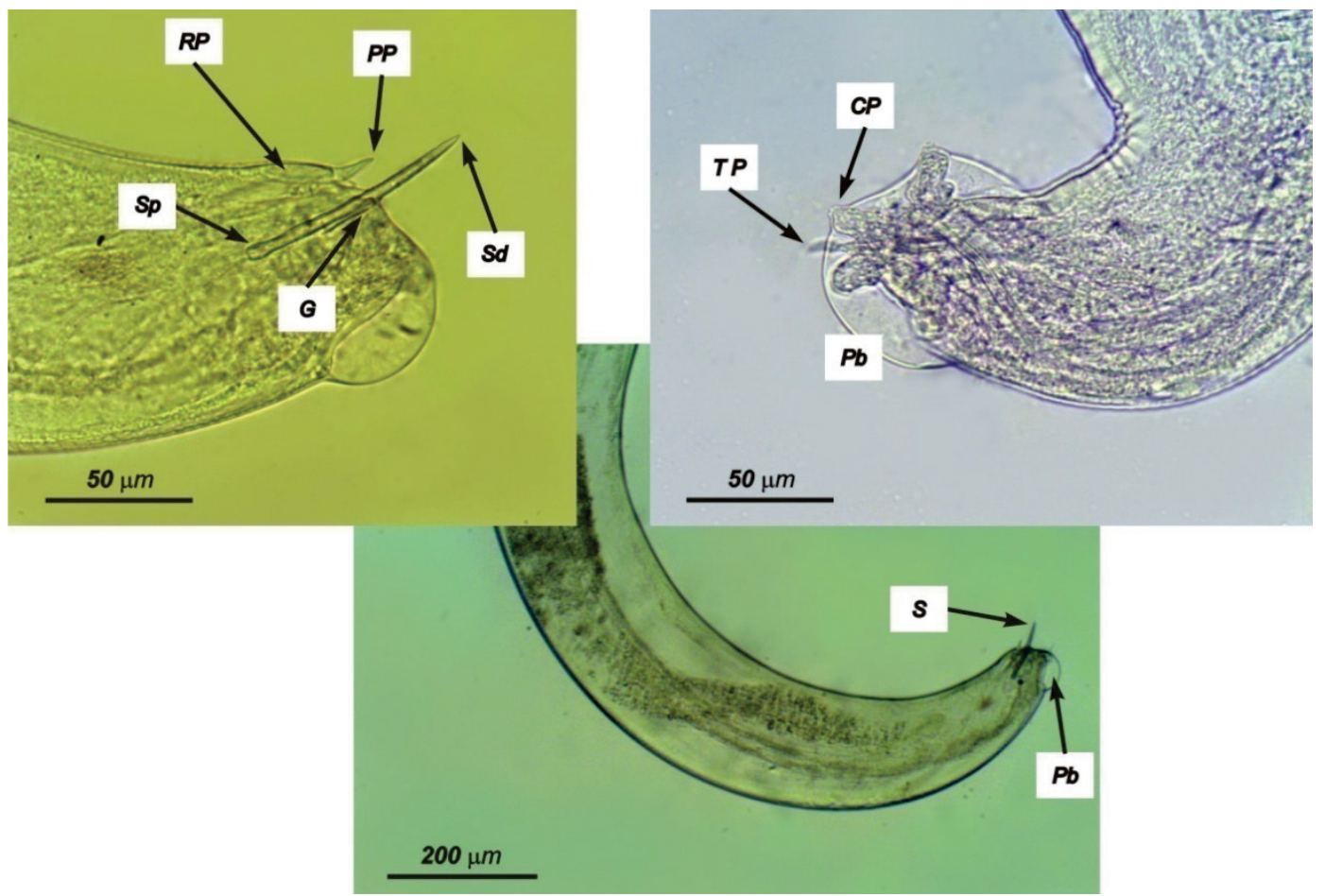

Fig. 4. Head end of $\widehat{\partial}$ Skrjabinema ovis: $P b$-pseudobursa, $R P$-ribbed papilla, $S$-spicule, $S p$-proximal end of spicule, $S d$-distal end of spicule, $G$ - gubernaculum, $P P$ - post-anal papilla, $C P$ - conic protrusions on the ribbed papilla, $T P$ - tail protrusion 


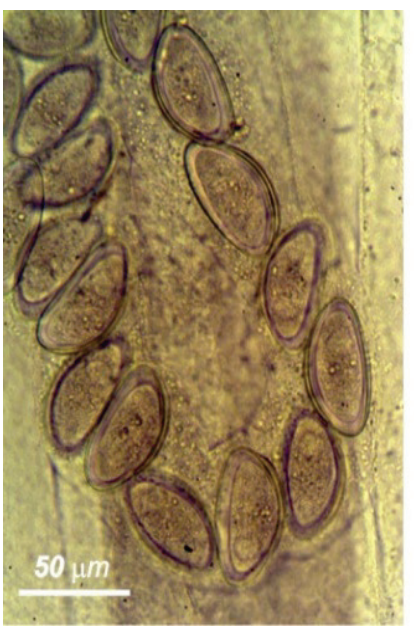

$a$
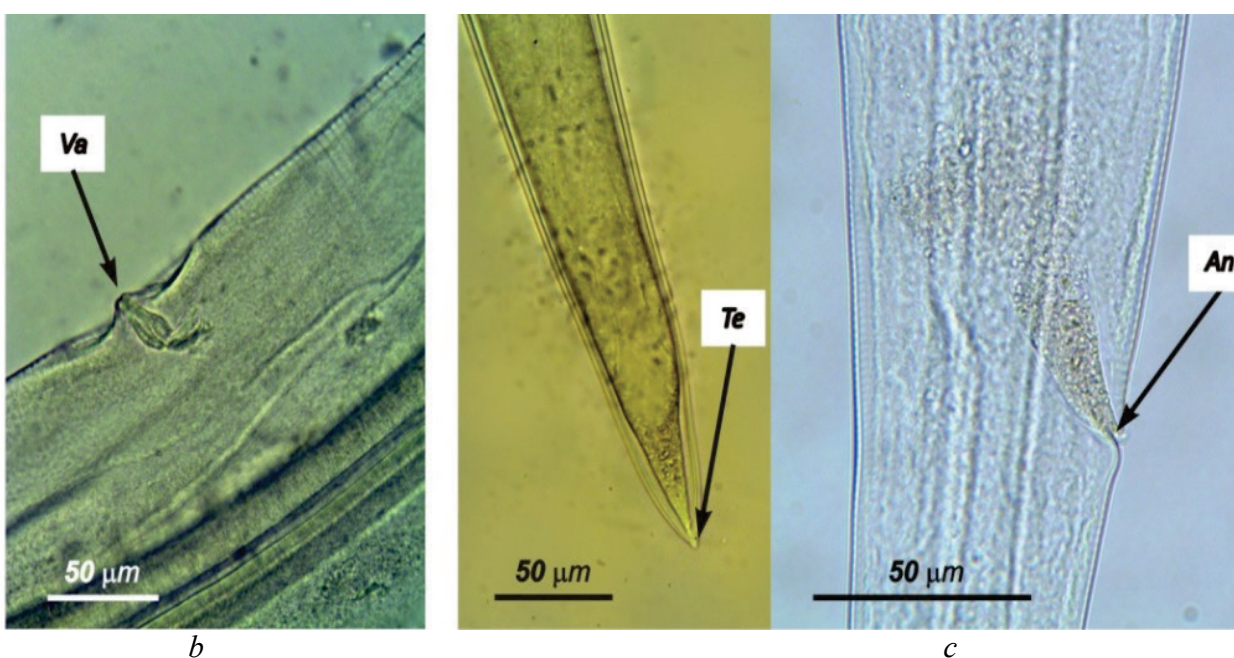

$c$

Fig. 5. + Skrjabinema ovis: $a$-uterus with eggs, $b$ - vulva area, $c$-tail end; $V a$-vulva area, $A n$-anus, $T e$ - tail end

Table 2

Metric parameters of $\widehat{\partial}$ Skrjabinema ovis nematodes $(\mathrm{n}=15, \mathrm{x} \pm \mathrm{SD}$, min - max)

\begin{tabular}{|c|c|c|c|}
\hline Parameters & Present study & Skrjabin et al., 1960 & Ivashkin et al., 1998 \\
\hline Length of pseudobursa, $\mu \mathrm{m}$ & $185.6 \pm 15.5(159.6-208.0)$ & - & - \\
\hline Width of pseudobursa, $\mu \mathrm{m}$ & $120.7 \pm 8.0(103.6-133.0)$ & - & - \\
\hline Ratio of length to width of pseudobursa & $1.5: 1(1.2: 1-1.9: 1)$ & & - \\
\hline Length of spicule, $\mu \mathrm{m}$ & $94.4 \pm 4.6(86.5-102.3)$ & $90-120$ & $90-120$ \\
\hline Width of proximal end of spicule, $\mu \mathrm{m}$ & $5.7 \pm 0.2(5.1-6.0)$ & - & - \\
\hline Width of spicule in the middle, $\mu \mathrm{m}$ & $4.4 \pm 0.2(4.1-4.8)$ & - & - \\
\hline Length of gubernaculum, $\mu \mathrm{m}$ & $24.4 \pm 2.1(20.1-27.1)$ & $19-24$ & - \\
\hline Width of proximal end of gubernaculum, $\mu \mathrm{m}$ & $5.3 \pm 0.1(5.0-5.6)$ & - & - \\
\hline Width of gubernaculum in the middle, $\mu \mathrm{m}$ & $4.0 \pm 0.4(3.2-4.7)$ & - & - \\
\hline
\end{tabular}

Note: “-" parameters were not defined.

Table 3

Metric parameters of $q$ Skrjabinema ovis nematodes $(\mathrm{n}=15, \mathrm{x} \pm \mathrm{SD}$, $\min -\max )$

\begin{tabular}{|c|c|c|c|}
\hline Parameters & Present study & Skrjabin et al., 1960 & Ivashkin et al., 1998 \\
\hline Width of body in vulva area, $\mu \mathrm{m}$ & $422.4 \pm 10.4(408.2-449.3)$ & - & - \\
\hline Distance from vulva to head end, $\mathrm{mm}$ & $2.1 \pm 0.1(1.9-2.3)$ & - & - \\
\hline Distance from vulva to anus, $\mathrm{mm}$ & $3.7 \pm 0.4(2.8-4.8)$ & - & - \\
\hline Distance from vulva to tail end, $\mathrm{mm}$ & $4.1 \pm 0.4(3.2-5.2)$ & - & - \\
\hline Distance from anus to tail end, $\mu \mathrm{m}$ & $338.3 \pm 26.9(290.9-392.1)$ & 900 & - \\
\hline Width of body in anus area, $\mu \mathrm{m}$ & $63.6 \pm 3.5(60.3-74.0)$ & 150 & - \\
\hline Ratio of distance from head end to vulva to distance from vulva to tail end & $0.5: 1(0.4: 1-0.6: 1)$ & $3: 5$ & - \\
\hline Egg length, $\mu \mathrm{m}$ & $57.5 \pm 2.2(52.6-60.2)$ & $55-63$ & $50-60$ \\
\hline Egg width, $\mu \mathrm{m}$ & $28.7 \pm 1.9(24.6-32.2)$ & 34 & 30 \\
\hline Eggshell thickness, $\mu \mathrm{m}$ & $2.0 \pm 0.1(1.8-2.3)$ & - & - \\
\hline
\end{tabular}

Note: “-"parameters were not defined.

The specific morphological characters of $S$. ovis females include the specifics of morphology of the vulva area, tail end, and shape of eggs in the uterus (Fig. 5), and their metric parameters (Table 3).

The tails of females are pointed and conical. Their copulatory apparatus is unpaired, and consists of one ovary, uterus, vagina and vulva. The vulva is slit-like, positioned as a pyramid on a slight elevation. The width of body at the vulva area was $422.4 \pm 10.4 \mu \mathrm{m}$. In contrast, the width of body at anus was $63.6 \pm 3.5 \mu \mathrm{m}$. The vulva is located in the anterior part of body, which is clear from the metric indices of its position. The distance from vulva to head end was smaller by $43.2 \%$, than the distance from vulva to tail end. The ratio of the distance from the head end to vulva to the distance from vulva to tail end was $0.5: 1$. The position of the anus on the bodies of Skrjabinema females should also be considered. The distance from anus to tail end was $338.3 \pm 26.9 \mu \mathrm{m}$, and the distance from vulva to anus was $3.7 \pm 0.4 \mathrm{~mm}$.

Eggs in the uterus are morphologically distinct. They are elliptic, asymmetrical, with one flatter side and one more convex. At one egg pole, there is a slight pointed process, distinct in well-developed eggs. Metrically, the eggs were $57.5 \pm 2.2 \mu \mathrm{m}$ long (ranging 52.6-60.2 $\mu \mathrm{m}$ ), and $28.7 \pm$ $1.9 \mu \mathrm{m}$ wide (24.6-32.2 $\mu \mathrm{m})$, with eggshell thickness of $2.0 \pm 0.1 \mu \mathrm{m}$ $(1.8-2.3 \mu \mathrm{m})$.

\section{Discussion}

Nematodes are one of the most diverse types within the animal kingdom. One of the directions of their evolutionary development was entering other living organisms, and creating various relationships from phoresy to true parasitism. As a result, a number of nematode taxa include both free-living and parasitic species, and the transitional forms. That is why nematodes are especially interesting for parasitology, allowing the study of the adaptations to parasitism in progress (Castagnone-Sereno \& Danchin, 2014; Lok, 2016; Viney, 2017). The nematodes of the order Oxyurida (Weinland, 1858) are parasitic. They can inhabit the intestines of arthropods, vertebrates, wild and domestic animals, and humans (Hugot et al., 1996; Ariyarathenam et al., 2010; Kim et al., 2013; Carreno et al., 2014).

Skrjabinema ovis (Skrjabin, 1915) is a representative of the underresearched Oxyurida parasites of ruminants. Reports on distribution of this nematode species in domestic sheep give the infection rates up to $12 \%$ (Bahadori et al., 2007; Naem \& Gorgani, 2011; de Souza et al., 2012). Thus, the more detailed study of differential specifics of $S$. ovis will help the timely and accurate diagnosis, and correspondingly, the understanding of the real epizootic situation in a given region. That will allow timely measures of prevention of skrjabinemosis infection in animals. 
In our study, additional parameters were found that will help better identification of $S$. ovis by males and females. The sexual dimorphism in S. ovis nematodes is significant, and the females are significantly $(\mathrm{P}<$ 0.001 ) larger by 11 parameters than males. We also described the morphological differences between the male and female roundworms. They are found in the structure of mouth organs: lips of females are anchorshaped and have one pair of tooth-like lamellae on their inner side. The lips of males are oval and lack the tooth-like lamellae. Similar morphological differences of the lips have been described in another study (Skjabin et al., 1960). We also suggest taking into account the shape and size of cuticular nodes at the head end: they are notably wider and longer in females than in males. We have not found any reports of such differences in S. ovis in previous publications.

We also suggest taking into account the metric parameters of S. ovis. Nine parameters are of interest in males, namely: length and width of the pseudobursa, ratio of these parameters, length of the spicule, width of the spicule at the proximal end and in the middle, length of the gubernaculum, width of the gubernaculum at the proximal part and in the middle. In females, seven parameters are notable: width of the body in the vulva area and anus area, distances from vulva to head end and from vulva to tail end and the ratio of these distances, distance from anus to tail end, and distance from vulva to anus. Scientific publications mention only a few scarce parameters, including the morphometric specifics of males and females. Those include length and width of body, length of esophagus, diameter of bulbus, distance from vulva to head and tail ends, lengths of spicule and gubernaculum (Shahlapoor, 1965; Ivashkin et al., 1998). We suggest also measuring the egg length and width, and eggshell thickness. The specific morphology of eggs is given in the identification keys, which mention the elliptical asymmetric shape of eggs (Andrews, 1969; Anderson, 2000), confirmed in our studies too.

The conducted morphological studies show that the morphological specifics of the pseudobursa, the presence and number of papillae that support the membrane, the position and shape of spicule and gubernaculum can be considered as differential characters of the species. In females, the morphology of the vulva and shape of the tail end should be considered. The importance of such parameters in identification of $S$. ovis nematodes has been pointed out in several publications where a number of differential features of the copulatory apparatus have been described for male and female roundworms (Schad, 1957; Skjabin et al., 1960; Ivashkin et al., 1998).

The additional suggested morphometric parameters that can be used in differentiation of male and female $S$. ovis will enhance the efficiency of their identification.

\section{Conclusion}

It is established that the morphological and metric parameters of males and females should be considered in the species identification of Skrjabinema ovis Skrjabin, 1915 nematodes. The sexual dimorphism in $S$. ovis is significant and distinct, the females are larger by 11 parameters than males. We also found differences in the morphology of the mouth organs and cuticular nodes at the head ends of the male and female parasites. Nine metric parameters are suggested in males, characterizing the structure of the pseudobursa, spicule, gubernaculum and the body sizes in the area of the copulatory apparatus. The morphology of the pseudobursa, which includes a complex structure of papillae as its base, is typical. In females, seven parameters are suggested relating to the position of vulva, anus, and body sizes at those areas. The morphological criterion of differentiation of females is the specifics of vulva and tail end shapes. Additional characters for the taxonomical evaluation of $S$. ovis may include the metric and morphological parameters of their eggs, such as shape, structure, length, width and eggshell thickness.

\section{References}

Abdelnabi, G. H., Elowni, E. E., \& Abdalla, H. S. (2005). Some helminths from the gastrointestinal tract of sheep in the Sudan. Sudan Journal of Veterinary Research, 20, 87-88

Abdussalam, M. (1938). On the occurrence of Skrjabinema ovis (Skrjabin, 1915) in India. Proceedings of the Indian Academy of Sciences, 8, 15-17.
Anderson, R. C. (2000). Nematode parasites of vertebrates: Their development and transmission. 2nd ed. CABI Publish, Wallingford, Oxon.

Andrews, J. R. H. (1969). A guide to the identification of helminth parasites recorded from wild ruminants in New Zealand. Tuatara, 17(2), 67-81.

Anteneh, W., \& Yadav, K. R. (2017). A review sheep production system, yield, quality and preservation methods in Ethiopia. Greener Journal of Agricultural Sciences, 7(9), 243-254

Ariyarathenam, A. V., Nachimuthu, S., Tang, T. Y., Courtney, E. D., Harris, S. A., \& Harris, A. M. (2010). Enterobius vermicularis infestation of the appendix and management at the time of laparoscopic appendectomy: Case series and literature review. International Journal of Surgery, 8, 466-469.

Bahadori, S., Eslami, A., \& Aghabrahimi-Samani, R. (2007). Study on parasitic infection of the domestic ruminants in Golestan province. Journal of Veterinary Research, 62(5), 303-305.

Balbo, T., Costantini, R., Gallo, M. G., \& Lanfranchi, P. (1977). Sulla diffusione dei nematodi parassiti dell'apparato digerente in pecore (Ovis aries) e in capre $(\mathrm{Ca}$ pra hircus) dell'arco alpino piemontese e valdostano. Parassitologia, 19(1-2), $59-61$.

Banerjee, R., Mandal, P. K., Bose, S., Banerjee, M., \& Manna, B. (2009). Quality evaluation of meat, skin and wool from Garole sheep - a promising breed from India. Asian Joumal of Animal Sciences, 3, 39-46.

Belem, A., Kaboré, A., \& Bessin, R. (2005). Gastrointestinal helminthes of sheep in the central, eastem and northem parts of Burkina Faso. Bulletin of Animal Health and Production in Africa, 53(1), 13-23.

Boyko, O. O., Zazharska, N. M., \& Brygadyrenko, V. V. (2016). The influence of the extent of infestation by helminths upon changes in body weight of sheep in Ukraine. Visnyk of Dnipropetrovsk University, Biology, Ecology, 24(1), 3-7.

Carreno, R. A. (2014). The systematics and evolution of pinworms (Nematoda: Oxyurida: Thelastomatoidea) from invertebrates. Journal of Parasitology, 100(5), 553-560.

Castagnone-Sereno, P., \& Danchin, E. G. (2014). Parasitic success without sex - the nematode experience. Journal of Evolutionary Biology, 27(7), 1323-1333.

De Souza, M., Pimentel-Neto, M., da Silva, R. M., Farias, A. C., \& Guimarães, M. P. (2012). Gastrointestinal parasites of sheep, municipality of Lajes, Rio Grande do Norte, Brazil. Revista Brasileira de Parasitologia Veterinaria, 21(1), 71-73.

Farooq, Z., Mushtaq, S., Iqbal, Z., \& Akhtar, S. (2012). Parasitic helminths of domesticated and wild ruminants in Cholistan desert of Pakistan. International Journal of Agriculture and Biology, 14(1), 63-68.

Hugot, J. P., Gardner, S. L., \& Morand, S. (1996). The Enterobiinae subfam. nov. (Nematoda, Oxyurida) pinworm parasites of primates and rodents. International Journal for Parasitology, 26(2), 147-159.

Ibrahim, N., Tefera, M., Bekele, M., \& Alemu, S. (2014). Prevalence of gastrointestinal parasites of small ruminants in and around Jimma Town Western Ethiopia. Acta Parasitologica, 5, 26-32.

Ivashkin, V. M., Kontrimavichus, V. L., \& Nazarova, N. S. (1971). Methods for collection and study of helminths of terrestrial mammals [Metody sbora i izuchenija gel'mintov nazemnyh pozvonochnyh]. Nauka, Moscow (in Russian).

Ivashkin, V. M., Oripov, A. O., \& Sonin, M. D. (1998). The key to helminths of small cattle [Opredelitel' gel'mintov melkogo rogatogo skota]. Nauka, Moscow (in Russian).

Kim, D. H., Cho, M. K., Park, M. K., Kang, S. A., Kim, B. Y., Park, S. K., \& Yu, H. S. (2013). Environmental factors related to enterobiasis in a southeast region of Korea. The Korean Journal of Parasitology, 51, 139-142.

Li, Y., Chen, H. X., Yang, X. L., \& Li, L. (2019). Morphological and genetic characterization of Syphabulea tjanschani (Ablasov, 1962) (Nematoda: Oxyuridae), with phylogenetic position of Syphabulea in Oxyuridae. Infection, Genetics and Evolution, 67, 159-166.

Lok, J. B. (2016). Signaling in parasitic nematodes: Physicochemical communication between host and parasite and endogenous molecular transduction pathways governing worm development and survival. Current Clinical Microbiology, 3(4), 186-197.

Naem, S., \& Gorgani, T. (2011). Gastrointestinal parasitic infection of slaughtered sheep (Zel breed) in Fereidoonkenar city, Iran. Veterinary Research Forum, 2(4), 238-241.

Popiołek, M., Hildebrand, J., \& Zaleśny, G. (2009). Morphology and taxonomy of Rodentoxyuris sciuri Quentin et Tenora, 1974 (Nematoda: Oxyurida: Enterobiinae) with notes on molecular phylogeny. Annales Zoologici, 59(4), 415-421.

Rasali, D. P., Shrestha, J. N. B., \& Crow, G. H. (2006). Development of composite sheep breeds in the world: A review. Canadian Journal of Animal Science, 86(1), 1-24.

Roeber, F., Jex, A. R., \& Gasser, R. B. (2013). Impact of gastrointestinal parasitic nematodes of sheep, and the role of advanced molecular tools for exploring epidemiology and drug resistance - an Australian perspective. Parasites and Vectors, 6, 153.

Ruiz de Ybáñez, M. R., Garijo, M. M., Balanza, P., \& Alonso, F. (1999). Parásitos del intestino grueso del ganado ovino en la región de Murcia. Anales de Veterinaria de Murcia, 15, 25-36. 
Schad, G. A. (1957). Preliminary observations of the life history of the sheep pinworm, Skrjabinema ovis. Journal of Parasitology, 43, 13.

Shahlapoor, A. A. (1965). A note on the identification of Skrjabinema ovis (Skrjabin, 1915) and Trichostrongylus spp. in sheep and goats in Iran. Joumal of Helminthology, 39(2), 273-276.

Skjabin, K. I., Shikhobalova, N. P., \& Lagodovskaya, E. A. (1960). Fundamentals of nematodology. Oxyurata of animals and man [Osnovy nematodologii. Oksiuraty zhivotnyh i cheloveka]. Nauka, Moscow (in Russian).

Skrjabin, K. I. (1928). Metod polnyh gel'mintologicheskih vskrytij pozvonochnyh, vkljuchaja cheloveka [The method of complete helminthological autopsy of vertebrates, including humans]. Moscow State University, Moscow (in Russian).
Tariq, A. K., Chishti, M. Z., Ahmad, F., \& Shawl, A. S. (2008). Epidemiology of gastrointestinal nematodes of sheep managed under traditional husbandry system in Kashmir valley. Veterinary Parasitology, 158(1), 138-143.

Theodoridis, Y., Himonas, C., \& Papazahariadou, M. (2000). Helminths parasites of digestive trackt of sheep and goats in Macedonian region. Journal of the Hellenic Veterinary Medical Society, 51(3), 195-199.

Viney, M. (2017). How can we understand the genomic basis of nematode parasitism? Trends in Parasitology, 33(6), $444-452$.

Vlassoff, A., Leathwick, D. M., \& Heath, A. C. (2001). The epidemiology of nematode infections of sheep. New Zealand Veterinary Journal, 49(6), 213-221.

Zazharska, N., Boyko, O., \& Brygadyrenko, V. (2018). Influence of diet on the productivity and characteristics of goat milk. Indian Journal of Animal Research, 52(5), 711-717. 